\title{
Can we measure beauty? Computational evaluation of coral reef aesthetics
}

Andreas F Haas, Marine Guibert, Anja Foerschner, Tim Co, Sandi Calhoun, Emma George, Mark Hatay, Elizabeth Dinsdale, Stuart A Sandin, Jennifer E Smith, Mark Vermeij, Ben Felts, Phillip Dustan, Peter Salamon, Forest Rohwer

The natural beauty of coral reefs attracts millions of tourists worldwide resulting in substantial revenues for the adjoining economies. Although their visual appearance is a pivotal factor attracting humans to coral reefs current monitoring protocols exclusively target biogeochemical parameters, neglecting changes in their aesthetic appearance. Here we introduce a standardized computational approach to assess coral reef environments based on 109 visual features designed to evaluate the aesthetic appearance of art. The main feature groups include color intensity and diversity of the image, relative size, color, and distribution of discernable objects within the image, and texture. Specific coral reef aesthetic values combining all 109 features were calibrated against an established biogeochemical assessment (NCEAS) using machine learning algorithms. These values were generated for $\sim 2100$ random photographic images collected from 9 coral reef locations exposed to varying levels of anthropogenic influence across 2 ocean systems. Aesthetic values proved accurate predictors of the NCEAS scores (root mean square error $<5$ for $\mathrm{N} \geq 3$ ) and significantly correlated to microbial abundance at each site. This shows that mathematical approaches designed to assess the aesthetic appearance of photographic images can be used as an inexpensive monitoring tool for coral reef ecosystems. It further suggests that human perception of aesthetics is not purely subjective but influenced by inherent reactions towards measurable visual cues. By quantifying aesthetic features of coral reef systems this method provides a cost efficient monitoring tool that targets one of the most important socioeconomic values of coral reefs directly tied to revenue for its local population. 


\section{Can we measure beauty?}

\section{Computational evaluation of coral reef aesthetics}

Andreas F. Haas ${ }^{1}$, Marine Guibert ${ }^{2}$, Anja Foerschner ${ }^{3}$, Tim $\mathrm{Co}^{4}$, Sandi Calhoun ${ }^{1}$, Emma George $^{1}$, Mark Hatay ${ }^{1}$, Elizabeth Dinsdale ${ }^{1}$, Stuart A. Sandin ${ }^{5}$, Jennifer E. Smith ${ }^{5}$, Mark Vermeij ${ }^{6,7}$, Ben Felts ${ }^{4}$, Phillip Dustan ${ }^{8}$, Peter Salamon ${ }^{4}$ and Forest Rohwer ${ }^{1}$

${ }^{1}$ Department of Biology, San Diego State University, San Diego, USA

${ }^{2}$ École nationale supérieure de techniques avancées (ENSTA)-ParisTech, Université de ParisSaclay, Palaiseau, France

${ }^{3}$ The Getty Research Institute, Los Angeles, USA

${ }^{4}$ Department of Mathematics and Statistics, San Diego State University, San Diego, USA

${ }^{5}$ Scripps Institution of Oceanography, University of California San Diego, San Diego, USA

${ }^{6}$ Caribbean Research and Management of Biodiversity (CARMABI), Willemstad, Curacao

${ }^{7}$ Aquatic Microbiology, Institute for Biodiversity and Ecosystem Dynamics (IBED), University of Amsterdam, Netherlands

${ }^{8}$ Department of Biology, University of Charleston, Charleston, USA

\section{Abstract}

The natural beauty of coral reefs attracts millions of tourists worldwide resulting in substantial revenues for the adjoining economies. Although their visual appearance is a pivotal factor attracting humans to coral reefs current monitoring protocols exclusively target biogeochemical parameters, neglecting changes in their aesthetic appearance. Here we introduce a standardized computational approach to assess coral reef environments based on 109 visual features designed to evaluate the aesthetic appearance of art. The main feature groups include color intensity and diversity of the image, relative size, color, and distribution of discernable objects within the image, and texture. Specific coral reef aesthetic values combining all 109 features were calibrated against an established biogeochemical assessment (NCEAS) using machine learning algorithms. These values were generated for $\sim 2100$ random photographic images collected from 9 coral reef locations exposed to varying levels of anthropogenic influence across 2 ocean systems. Aesthetic values proved accurate predictors of the NCEAS scores (root mean square error $<5$ for $\mathrm{N} \geq 3$ ) and significantly correlated to microbial abundance at each site. This shows that mathematical approaches designed to assess the aesthetic appearance of photographic images can be used as an inexpensive monitoring tool for coral reef ecosystems. It further suggests that human perception of aesthetics is not purely subjective but influenced by inherent reactions towards measurable visual cues. By quantifying aesthetic features of coral reef systems this method provides a cost efficient monitoring tool that targets one of the most important socioeconomic values of coral reefs directly tied to revenue for its local population. 


\section{Introduction}

Together with fishing, cargo shipping, and mining of natural resources, tourism is one of the main economic values to inhabitants of coastal areas. Tourism is one of the world's largest businesses (Miller \& Auyong, 1991) and with ecotourism as the fastest growing form of it worldwide (Hawkins \& Lamoureux, 1997) the industry is increasingly dependent on the presence of healthy looking marine ecosystems (Peterson \& Lubchenco, 1997). In this context coral reefs are one of the most valuable coastal ecosystems. They attract millions of visitors each year through their display of biodiversity, their abundance of colors, and their sheer beauty and lie at the foundation of the growing tourism based economies of many small island developing states (Neto 2003; Cesar, Burke \& Pet-Soede, 2003).

Over the past decades the problem of coral reef degradation as a result of direct and indirect anthropogenic influences has been rigorously quantified (Pandolfi et al., 2003). This degradation affects not only the water quality, but also the abundance and diversity of the reefs inhabitants, like colorful reef fish and scleractinian corals. To assess the status of reef communities and to monitor changes in their composition through time, a multitude of monitoring programs have been established, assessing biophysical parameters such as temperature, water quality, benthic cover, and fish community composition (e.g., Jokiel et al., 2004; Halpern et al., 2008; Kaufman et al., 2011). These surveys however target exclusively on provisioning, habitat, and regulating ecosystem services and neglect their cultural services; i.e. the immediately nonmaterial benefits people gain from ecosystems (Seppelt et al., 2011; Martın-Lopez et al., 2012; Casalegno et al., 2013). Monitoring protocols to assess the biogeochemical parameters of an ecosystem, which need to be conducted by trained specialists to provide reliable data, will not give account of one of the most valuable properties of coastal environments: their aesthetic appearance to humans, which is likely the main factor prompting millions of tourists each year to visit these environments.

The value of human aesthetic appreciation for ecosystems has been studied in some terrestrial (e.g., Hoffman \& Palmer, 1996; Van den Berg, Vlek \& Coeterier, 1998; Sheppard 2004; Beza 2010; de Pinho et al., 2014) and marine ecosystems (Fenton \& Syme, 1989; Fenton, Young \& Johnson, 1998; Dinsdale \& Fenton, 2006). However most of these studies have relied on surveys, collecting individual opinions on the aesthetic appearance of specific animals or landscapes and are therefore hard to reproduce in other locations due to a lack of objective and generalizable assessments of aesthetic properties. A recent approach by Casalegno et al. (2013) 
objectively measures the perceived aesthetic value of ecosystems by quantifying geo-tagged digital photographs uploaded to social media resources.

Although relatively new in the context of ecosystem evaluation, efforts to define universally valid criteria for aesthetic principles have been existing since antiquity (e.g., Plato, Aristotle, Confucius, Laozi). Alexander Gottlieb Baumgarten introduced aesthetics in 1735 as a philosophical discipline in his Meditationes (Baumgarten \& Baumgarten, 1735) and defined it as the science of sensual cognition. Classicist philosophers such as Immanuel Kant, Georg Wilhelm Friedrich Hegel, or Friedrich Schiller, then established further theories of the "aesthetic," coining its meaning as a sense of beauty and connecting it to the visual arts. Kant (1790) also classified judgments about aesthetic values as having a subjective generality. In the $20^{\text {th }}$ and $21^{\text {st }}$ century, when beauty was not necessarily the primary sign of quality of an artwork anymore, definitions of aesthetics and attempts to quantify aesthetic values have reemerged as a topic of interest for philosophers, art historians, and mathematicians alike (e.g., Datta et al., 2006; Onians, 2007).

With the term aesthetics recipients usually characterize the beauty and pleasantness of a given object (Dutton, 2006). There are however various ways in which aesthetics is defined by different people as focus of interest and aesthetic values may change depending on previous attainment (Datta et al., 2006). For example, while some people may simply judge an image by the pleasantness to the eye, another artist or professional photographer may be looking at the composition of the object, the use of colors and light, or potential additional meanings conveyed by the motive (Datta et al., 2006). Thus assessing the aesthetic visual quality of paintings seems, at first, to pose a highly subjective task (Li \& Chen, 2009). Contrary to these assumptions, various studies successfully applied mathematical approaches to determine the aesthetic values of artworks such as sculptures, paintings, or photographic images (Datta et al., 2006; Li \& Chen, 2009; Ke, Tang \& Jing, 2006). The methods used are based on the fact that certain objects or certain features in them have higher aesthetic quality than others (Datta et al., 2006; Li \& Chen, 2009). The overarching consensus hereby is that objects, or images, which are pleasing to the eye, are considered to be of higher value in terms of their aesthetic beauty. The studies which inspired the metrics used in our current work successfully extracted distinct features based on the intuition that they can discriminate between aesthetically pleasing and displeasing images. By constructing high level semantic features for quality assessment these studies have established a significant 
104 correlation between various computational properties of photographic images and their aesthetics

105 perceptions by humans (Datta et al., 2006; Li \& Chen, 2009).

Methods

Study sites: Four atolls across a gradient of human impact served as basis for this study.

The 4 islands are part of the northern Line Islands group located in the central pacific. The most northern atoll Kingman has no population and is, together with Palmyra which is exposed to sparse

111 human impact, part of the US national refuge system. The remaining two atolls Tabuaeran and

112 Kiritimati are inhabited and part of the Republic of Kiribati (Dinsdale et al., 2008; Sandin et al.,

113 2008). To extend the validity of the method proposed here to other island chains and ocean systems

114 we included an additional sampling site in the Central Pacific (Ant Atoll) and four locations in the

115 Caribbean also subjected to different levels of human impact (2 sites on Curacao, Klein Curacao,

116 and Barbuda). From every location we collected sets of $172 \pm 17$ benthic photo-quadrant (Preskitt,

117 Vroom \& Smith, 2004) and $63 \pm 9$ random pictures. To evaluate the level of human impact and

118 status of the ecosystem we used the cumulative global human impact map generated by the

119 National Center for Ecological Analysis and Synthesis (NCEAS;

120 http:/www.nceas.ucsb.edu/globalmarine/impacts). These scores incorporate data related to:

121 artisanal fishing; demersal destructive fishing; demersal non-destructive, high-bycatch fishing;

122 demersal non-destructive low-bycatch fishing; inorganic pollution; invasive species; nutrient

123 input; ocean acidification; benthic structures; organic pollution; pelagic high-bycatch fishing;

124 pelagic low-bycatch fishing; population pressure; commercial activity; and anomalies in sea

125 surface temperature and ultraviolet insolation (Halpern et al., 2008; McDole et al., 2012).

126 Additionally, bacterial cell abundance across the 4 Northern Line Islands and 3 of the Caribbean

127 locations (Curacao main island and Barbuda; table 1) were measured after the method described

128 by Haas et al. (2014).

129 Aesthetic feature extraction: In total we extracted, modified, and complemented 109

130 features (denoted as $f_{1}, f_{2}, \ldots, f_{109}$ ) from three of the most comprehensive studies on computational

131 approaches to aesthetically evaluate paintings and pictures (table S1; Datta et al., 2006; Li \& Chen,

132 2009; Ke, Tang \& Jing, 2006). Aesthetic evaluation of paintings and photographs in all three

133 studies were based on surveys of randomly selected peer groups. Some of the features presented

134 in previous work were however difficult to reproduce owing to insufficient information given on 
135 these features (e.g., f16 - 24, or f51). This may have led to slight alterations in some of the codes

136 which were inspired by the suggested features but deviate slightly in their final form. As the

137 pictures were considered to be objective samples representing the respective seascape, some

138 traditional aesthetic features, like size of an image or its aspect ratio have not been considered in

139 this study. Overarching feature groups considered in the picture analysis were color, texture,

140 regularity of shapes, and relative sizes and positions of objects in each picture.

141 Aesthetic value: Although some of the implemented codes appeared similar and were 142 assessing closely related visual aspects, all of the suggested codes were implemented and their 143 value, or potential redundancy, was evaluated using machine learning algorithms. Following 144 feature extraction the 109 feature values were used as input for feed forward neural networks that 145 optimize the importance of features or feature groups and generate a single aesthetic value for each 146 respective photograph. The target outputs for the training of the networks were the NCEAS scores 147 of the regions where the pictures were taken. The pictures were randomly separated into a batch 148 used for training the machine learning algorithms $(\mathrm{N}=1897)$ and one on which the algorithms were tested $(\mathrm{N}=220,20$ from each of 11 sites). We used Matlab's neural network package on the training samples which further subdivided these samples into training (70\%), validation (15\%) and test $(15 \%)$ sets (See appendix for details). Unlike previous studies in which the aesthetic quality was classified in given categories, this machine learning regression approach allows to generate a continuous metric for the aesthetic quality of a given reefscape.

\section{Results}

An aesthetic value of coral reef images was defined using features previously created for measuring the aesthetic quality of images. The values were calibrated using machine learning to match NCEAS scores as closely as possible. Our algorithm could glean the NCEAS score from an image to within a root mean squared (rms) error of 6.57. Using five images from the same locale improved the NCEAS score prediction to an rms error of 4.46. The relative importance for each feature derived from a random forest approach showed that all three overarching feature groups, texture, color of the whole image, and the size, color, and distribution of objects within an image yielded important information for the algorithm (figure S1). The ten most important features, or feature groups were hereby the similarity in spatial distribution of high frequency edges, the wavelet features, number of color based cluster, the area of bounding boxes containing a given 
166 percentage of the edge energy, the average value of the HSV color space, entropy of the blue 167 matrix, range of texture, the arithmetic and the logarithmic average of brightness, and the 168 brightness of the focus region as defined by the rule of thirds.

169 The mean coral reef aesthetic values generated with this approach for each picture were 170 significantly different $(\mathrm{p}<0.001)$ between all sampling locations except for Ant Atoll, Fanning and Klein Curacao (ANOVA followed by Tukey, See table S2). These sites are also exposed to comparable levels of anthropogenic disturbance (NCEAS: 14.11 - 19.48). Regression of coral reef aesthetic values against the NCEAS scores of the respective sampling site showed a significant correlation $(p<0.001)$ for both the training $\left(n=1897, R^{2}=0.93\right)$ and the test $\left(n=220, R^{2}=0.80\right)$ set of images (figure 2). Further comparison to microbial abundance, available for 7 of the 9 locations (microbial numbers for Curacao Buoy2 and Ant Atoll were not available), revealed a significant correlation between the aesthetic appearance of the sampling sites and their microbial density $\left(\mathrm{p}=0.0006, \mathrm{R}^{2}=0.88\right.$; figure 3$)$.

\section{Discussion}

This is the first study using standardized computational approaches to establish a sitespecific correlation between aesthetic value, ecosystem degradation, and the microbialization (McDole et al., 2012) of marine coral reef environments.

Human response to visual cues

The connection between reef degradation and loss of aesthetic value for humans seems intuitive but initially hard to capture with objective mathematical approaches. Dinsdale (2009) showed that human visual evaluations provided consistent judgment of coral reef status regardless of their previous knowledge or exposure to these particular ecosystems. The most important cue was the perceived health status of the system. Crucial for this intuitive human response to degraded or "unhealthy" ecosystems is the fact that we are looking at organic organisms and react to them with the biological innate emotion of disgust (Curtis, 2007; Hertz, 2012). Being disgusted is a genetically anchored reaction to an object or situation, which might be potentially harmful to our system. Often, a lack of salubriousness of an object or situation is the crucial element for our senses, one of them visual perception, to signal us to avoid an object or withdraw from a situation 
197 reefs are significantly elevated (Dinsdale et al., 2008) - albeit not visible to the human eye - our 198 inherent human evaluation of degraded reefs as aesthetically unpleasing, or even disgusting, is nothing else than recognizing the visual effects of these changes as a potential threat for our wellbeing. Generally the emotion of disgust protects the boundaries of the human body and prevents potentially harmful substances from compromising the body. This theory was supported by French physiologist Charles Richet (1984), who described disgust as an involuntary and hereditary emotion for self-protection. The recognition of something disgusting, and thus of a lack of aesthetic value, prompts an intuitive withdrawal from the situation or from the environment triggering this emotion. Recent evolutionary psychology largely follows this thesis and concludes that disgust, even though highly determined by a certain social and cultural environment, is genetically imprinted and triggered on a biological level by objects or environments which are unhealthy, infectious, or pose a risk to the human wellbeing (Rozin \& Fallon, 1987; Rozin \& Schull, 1988; Foerschner, 2011). Decisive here is the connection between disgust and the salubriousness, or better lack thereof, of given objects, which indicates unhealthiness. Our here presented study supports these theories by establishing objectively quantifiable coral reef aesthetic values for ecosystems along a gradient of reef degradation, and for a subset microbial abundance. Perception of aesthetic properties is not purely a subjective task and measurable features of aesthetic perception are inherent to human nature. The main visual features assessed by our analysis are color intensity and diversity, relative size and distribution of discernable objects, and texture (figure S1, table S1). Human perception of each of these features does not only trigger innate emotions, each of these features also yields palpable information on the status of the respective ecosystem.

Color: Thriving ecosystems are abounding with bright colors. On land photosynthesizing plants display a lush green and, at least seasonally, blossoms and fruits in every color. Animals display color for various reasons, for protective and aggressive resemblance, protective and aggressive mimicry, warning colors, and colors displayed in courtship (Cope, 1890). Underwater, coral reefs surpass all other ecosystems in their display of color. The diversity and colorfulness of fauna and flora living in healthy reef systems is unmatched on this planet (Marshall, 2000; Kaufman, 2005). This diverse and intense display of color is, however, not only an indicator of high biodiversity, but also of a "clean" system. The brightest and most diverse display of colors 
228

229

230

231

232

233

234

235

236

237

238

239

240

241

242

243

244

245

246

247

248

249

250

251

252

253

254

255

256

257

258

suggest an evolutionary theory in the human preference of color patterns as a result of behavioral adaptations. Hurlbert and Ling (Hurlbert \& Ling, 2007) conclude that color preferences are engrained into human perception as neural response to selection processes improving performance on evolutionarily important behavioral tasks. Humans were more likely to survive and reproduce successfully if they recognize objects or environments that characteristically have colors which are advantageous/disadvantageous to the organism's survival, reproductive success, and general well-being (Palmer \& Schloss, 2010). Thus it is again not surprising that humans are inherently drawn to places with bright and diverse colors as they represent clean systems not associated with pollution or other health risks.

Objects: Not only does the visual brain recognize properties like luminance or color, it also segregates higher-order objects (Chatterjee, 2014). The relative size, distribution and regularity of objects in the pictures analyzed were important features in determining the aesthetic value of pictures. Birkhoff (1933) proposed in his theory of preference for abstract polygon shapes that aesthetic preference varies directly related to the number of elements. Further it has been established that people tend to prefer round regular and convex shapes as they are more symmetrical and structured (Jacobsen \& Höfel, 2002; Palmer \& Griscom, 2013). The fluency theory provides an additional explanation for a general aesthetic preference for specific objects (Reber, Winkielman \& Schwarz, 1998; Reber, Schwarz \& Winkielman, 2004; Reber, 2012). It predicts aesthetic inclination as a result of many low-level features (Oppenheimer \& Frank, 2008), like preferences for larger (Silvera, Josephs \& Giesler, 2002), more symmetrical (Jacobsen \& Höfel, 2002), more contrastive objects (Reber, Winkielman \& Schwarz, 1998; reviewed in Reber, Schwarz \& Winkielman, 2004). From a biological view there may be additional causes for the preference of larger discernable objects. Bigger objects representing living entities indicate that the environment is suitable for large animals and can provide a livelihood for apex predators like humans, while small objects suggest a heavily disturbed system, unable to offer resources for growth or a long life experience for its inhabitants. The lack of discernable objects like fish, hard corals, or giant clams suggests that microbiota are dominant in this system, likely at the expense of the macrobes (McDole et al., 2012).

Texture: Another important criterion in the aesthetic evaluation of an image is the existence of clearly discernible outlines; a distinguishable boundary texture that keeps objects separated from their environment. The Russian philosopher Mikhail Bakhtin (1941) elevated this 
259

260

261

262

263

264

265

266

267

268

269

270

271

272

273

274

275

276

277

278

279

280

281

282

283

284

285

286

287

288

289

characteristic to be the main attribute of grotesqueness in relation to animated bodies. Anything that disrupts the outline, all orifices or products of inner, bodily processes such as mucus, saliva, or semen evokes a negative emotional response of disgust and repulsion (Foerschner, 2011; 2013). Even though various theories on triggers for disgust exist, the absence of discernable boundaries (both physical and psychological) are fundamental to all of them (Foerschner, 2011; Menninghaus, 2012). For living organisms the transgression of boundaries and the dissolution of a discernable surface texture signify much more than the mere loss of form: it comprehends the organism in a state of becoming and passing, ultimately in its mortality. Decomposition, disease, and decay are as disgusting to us as mucus, saliva, or slime; the former in their direct relation to death, the latter ones as products of bodily functions, which equally identifies our organic state as transient (Kolnai, 2004). Further, amorphous slime covering and obscuring the underlying texture of objects may be the result of biofilm formation. A biofilm is a group of microorganisms which, frequently embedded within a mucoidal matrix, adheres to various surfaces. These microbial assemblages are involved in a wide variety of microbial infections (Costerton, Stewart \& Greenberg, 1999). Human perception is therefore more likely to evaluate a viscous, slimy, or amorphous object surface as repulsive whereas surface textures with clearly defined boundaries and patterns are pleasing to our senses and generally deemed aesthetic.

It has to be mentioned that by no means do we claim to provide an assessment for the value of art or artistic images by this method. The value of an artwork depends not only on the aesthetics, but also on the social, economic, political or other meanings it conveys (Adorno, 1997), and on the emotions and impulses it triggers in a recipient. However this study suggests that perception of aesthetic properties may be more objective than commonly appraised and patterns of aesthetic evaluation are inherent to human perception.

\section{Crowd sourcing \& Historic data mining}

The approach provided here will likely be a valuable tool to generate assessments on the status of reef ecosystems, unbiased by the respective data originator. By taking a set of random photographic images from a given system information on the aesthetic value and thus on the status of the ecosystem can be generated. Contrary to all previously introduced monitoring protocols the objective analysis of pictures will overcome bias introduced by the individual taking samples or analyzing the respective data. Obviously, the analysis of a single picture will depend on the motive 
290

291

292

293

294

295

296

297

298

299

300

301

302

303

304

305

306

307

308

309

310

311

312

313

314

315

316

317

318

319

320

chosen or camera handling and not every single picture will accurately reflect the status of the ecosystem (figure 4). However, as in most ecological approaches the accuracy of the information increases with sample size, i.e. number of digital images available (see figure 3B). The application of this method to resources like geo-tagged digital image databases or historic images of known spatial and temporal origin will allow access to an immense number of samples and could provide objective information on the status and the trajectories of reefs around the world. Previous studies already focused on the problem of establishing a baseline for pristine marine ecosystems, especially coral reefs. But coral reefs are among the most severely impacted systems on our planet (Knowlton, 2001; Wilkinson, 2004; Bellwood et al., 2004; Pandolfi et al., 2005; Hoegh-Guldberg et al., 2007) and most of the world's tropical coastal environments are so heavily degraded that pristine reefs are essentially gone (Jackson et al., 2001; Knowlton \& Jackson, 2008). The here presented method could provide a tool to establish a global baseline of coral reef environments, dating back to the first photographic coverage of the respective reef systems. As an example we used photographic images of the Carysfort reef in the US Caribbean, taken at the same location over a time span of nearly 40 years $(1975$-2014). The image analysis showed a clear degradation of aesthetic values during those four decades (figure 5). While the aesthetic appearance of this Caribbean reef in 1975 is comparable to reefscapes as they are found on remote places like the Palmyra atoll today, the aesthetic value drastically declined over the 40 year time span and place the aesthetic appearance of this reef below the heavily degraded reef sites of Kiritimati today (2004 and 2014).

\section{Socioeconomic assessment for stakeholders}

This study provides an innovative method to objectively assess parameters associated with a general aesthetic perception of marine environments. Although converting the aesthetic appearance of an entire ecosystem in simple numbers will likely evoke discussions and in some cases resentment, it may provide a powerful tool to disclose effects of implementing conservation measurements on the touristic attractiveness of coastal environments to stakeholders. The approach allows for a rapid analysis of a large number of samples and thus provides a method to cover ecosystems on large scale. Linking aesthetic values to cultural benefits and ultimately revenue for the entire community may be an incentive to further establish and implement protection measurements and could help to evaluate the success and the value to the community 
321 of existing conservation efforts. Using monitoring cues that directly address inherent human

322 emotions will more likely motivate and sustain changes in attitude and behavior towards a more 323 sustainable usage of the environmental resources than technical terms and data that carry no local 324 meaning (Carr, 2002; Dinsdale, 2009). Quantifying the aesthetic appearance of these ecosystems 325 targets on one of the most important socioeconomic values of these ecosystems, which are directly 326 tied to culture and the revenue of its local population.

\section{Appendix}

\section{Feature extraction}

\section{Global Features}

Global features are computed over all the pixels of an entire image.

332

333

334

335

336

337

338

339

340

341

342

344

The HSL (hue, saturation, lightness) and HSV (hue, saturation, value) color spaces are the two most common cylindrical-coordinate representations of points in an RGB color model. The HSV and HSL color space define pixel color by its hue, saturation and value, respectively lightness (Joblove \& Greenberg, 1978). This provides a color definition similar to the human visual perception. The first step for each picture analysis was therefore to calculate the average hue, saturation and value respectively lightness for both color spaces. Assuming a constant hue, the definition of saturation and of value and lightness are very much different. Therefore hue, saturation, and value of a pixel in the HSV space will be denoted as $I_{H}(m, n), I_{S}(m, n)$ and $I_{V}(m, n)$, and hue, saturation and lightness in the $\mathrm{HSL}_{\text {space }} I_{H_{-}}(m, n), I_{S_{-}}(m, n)$ and $I_{L_{-}}(m, n)$ from here on, where $m$ and $n$ are the number of rows and columns in each image. 
348 To assess colorfulness the RGB color space was separated in 64 cubes of identical volume by 349 dividing each axis in four equal parts. Each cube was then considered as individual sample point

350

351

352

353

354

355

356

357

358

359

360

361

362

363

364

365

366

367

368

369

370

371

372

373

374

375

376

377

and color distribution $D_{1}$ of each image defined as the frequency of color occurrence within each of the 64 cubes. Additionally a reference distribution $\mathrm{D}_{0}$ was generated so that each sample point had a frequency of $1 / 64$. The colorfulness of an image was then defined as distance between these two distributions, using the Quadratic-form distance (Ke, Tang \& Jing, 2006) and the Earth Mover's Distance (EMD). Both features take the pair-wise euclidian distances between the sample points into account. Assuming $c_{i}$ is now the center position of the $i$-th cube, we get $d_{i j}$ $=\left\|\operatorname{rgb} 2 \operatorname{luv}\left(c_{i}\right)-\operatorname{rgb} 2 \operatorname{luv}\left(c_{j}\right)\right\|_{2}$ after a conversion to the LUV (Adams chromatic valence space; Adams, 1943) color space. This leads to

$$
f_{6}=\sqrt{(h-h 0) T A(h-h 0)} \quad \text { and } \quad f_{7}=\operatorname{emd}\left(D_{1}, D_{0},\left\{d_{i j} \mid 1<i, j<64\right\}\right)
$$

in which $h$ and $h_{0}$ are vectors listing the frequencies of color occurrence in $D_{1}$ and $D_{0} . A=\left(a_{i j}\right)$ is a similarity matrix with $a_{i j}=1-d_{i j} / d_{\max }$ and $d_{\max }=\max \left(d_{i j}\right)$; 'emd' denotes the earth mover's distance we implemented using an algorithm described by Rubner et al. (2000).

For color analysis only pixels with a saturation $I_{-} \_(m, n)<0.2$ and a lightness $\mathrm{I}_{\mathrm{L}_{-}} \in[0.15$, 0.95] were used as the human eye is unable to distinguish hues and only sees shades of grey outside this range. As $P_{H}=\left\{\left(m^{\prime}, n^{\prime}\right) \mid I S_{-}>0.2\right.$ and $\left.0.15<I L_{-}<0.95\right\}$ represents the set of pixels whose hues can be perceived by humans, $f_{8}$ was defined as the most frequent hue in each image and $f_{9}$ as the standard deviation of colorfulness.

$$
f_{8}=\min \left(h_{\max }\right), \quad(7)
$$

where $\forall$ hue h, \# of $\left\{\left(m^{\prime}, n^{\prime}\right) \in P_{H} \mid I_{H_{-}}=h_{\max }\right\} \geq \#$ of $\left\{\left(m^{\prime}, n^{\prime}\right) \in P_{H} \mid I_{H_{-}}=h^{\prime}\right.$. If hues had an identical cardinal, the smallest one was chosen.

$$
f_{9}=\operatorname{std}\left(\operatorname{var}\left(I^{\prime}{ }_{H}\right)\right) \text {, }
$$

where $I_{H_{-}}^{\prime}(m, n)=I_{H_{-}}(m, n)$ if $(m, n) \in P_{H}$; otherwise $I_{H_{-}}^{\prime}(m, n)=0 . \operatorname{var}\left(I_{H_{-}}^{\prime}\right)$ is the vector containing the variance of each column of $I^{\prime} H_{-}$, and std returns its standard deviation.

The hue interval $[0,360]$ was then uniformly divided into 20 bins of identical size and computed into a hue histogram of the image. $Q$ represents the maximum value this histogram and the hue count was defined as the number of bins containing values greater than $C \bullet Q$. The number of missing hues represents bins with values smaller than $\mathrm{c} \cdot \mathrm{Q}$. $\mathrm{C}$ and $\mathrm{c}$ was set to 0.1 and 0.01 , respectively. 
378

380

381

382

383

384

385

386

387

388

389

390

391

392

393

394

395

396

397

398

399

400

401

402

403

404

$$
\begin{aligned}
& f_{10}=\# \text { of }\{i \mid h(i)>C \cdot Q\} \\
& f_{11}=\# \text { of }\{i \mid h(i)<c \cdot Q\}
\end{aligned}
$$

Hue contrast and missing hues contrast was computed as:

$$
\begin{aligned}
& f_{12}=\max \left(\left\|c_{h}(i)-c_{h}(j)\right\|_{a l}\right) \text { with } i, j \in\{i \mid h(i)>C \cdot Q\} \\
& f_{13}=\max \left(\left\|c_{h}(i)-c_{h}(j)\right\|_{a l}\right) \text { with } i, j \in\{i \mid h(i)<c \cdot Q\}
\end{aligned}
$$

where $c_{h}(i)$ is the center hue of the $i$-th bin of the histogram and $\|\bullet\|_{a l}$ refers to the arc-length distance on the hue wheel. $f_{14}$ denotes the percentage of pixels belonging to the most frequent hue:

$$
f_{14}=Q / N \text { where } N=\# \text { of } P_{H}
$$

$$
f_{15}=20-\# \text { of }\left\{i \mid h(i)>C_{2} \cdot Q\right\} \text { with } C_{2}=0.05
$$

\section{Color models}

As some color combinations are more pleasant for the human eye than others ( $\mathrm{Li} \& \mathrm{Chen}$, 2009), each image was fit against one of 9 color models (figure S2 K). As the models can rotate, the $k$-th model rotated with an angle $\alpha$ as $M_{k}(\alpha), G_{k}\left(\mathrm{I}_{\mathrm{H}_{-}}(\mathrm{m}, \mathrm{n})\right.$ was assigned to the grey part of the respective model. $E_{M k(\alpha)}(m, n)$ was defined as the hue of $G_{k}(\alpha)$ closest to $\mathrm{I}_{\mathrm{H}_{-}}$.

$$
E_{M k(\alpha)}(m, n)=\left\{\begin{array}{c}
I H_{-}(m, n) \text { if } I H_{-}(m, n) \in G k(\alpha) \\
\text { Hnearestborder if } I H_{-}(m, n) \notin G k(\alpha)
\end{array}\right\}
$$

where $\mathrm{H}_{\text {nearestborder }}$ is the hue of the sector border in $M_{k}(\alpha)$ closest to the hue of pixel $(\mathrm{m}, \mathrm{n})$. Now the distance between the image and the model $M_{k}(\alpha)$ can be computed as

$$
F_{k, \alpha}=\frac{1}{\sum_{m} \Sigma_{m} I S_{-}(m, n)} \sum_{n} \sum_{m}\left\|E_{M k(\alpha)}(m, n)-I_{H_{-}}(m, n)\right\|_{a l} \bullet I_{S_{-}}(m, n)
$$

with $I_{S_{-}}(m, n)$ accounting for less color differences with lower saturation. This definition of the distance to a model was inspired by Datta et al. (2006) with the addition of a normalization $\frac{1}{\sum_{m} \sum_{n} I s_{-}(m, n)}$ W to each model yield more information than the identity of the single model the image fits best, all distances were calculated and features $f_{16}-f_{24}$ are therefore defined as the smallest distance to each model:

$$
f_{15+k}=\min _{\alpha} F_{k, \alpha}, \quad k \in\{1, \ldots, 9\}
$$

Theoretically the best fitting hue model could be defined as $M_{k o}\left(\alpha_{o}\right)$ with

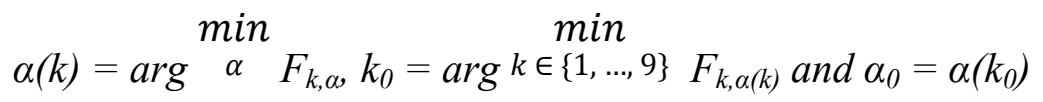


405 Those models are, however, very difficult to fit. Therefore we set a threshold $T H$ assuming that if $406 F_{k, \alpha(k)}<T H$, the picture fits the $k$-th color model. If $\forall \mathrm{k} F_{k, \alpha(k)} \geq T H$, the picture was fit to the closest 407 model. In case several models could be assigned to an image not the closest one, but the most 408 restrictive was chosen. As the color models are already ordered according to their restrictiveness 409 the fit to the color model we characterize as:

$$
f_{25}=\left\{\begin{array}{lr}
\operatorname{maxk} \in\{j \mid F j, \alpha(j), T H\} & k \text { if } \exists k \in\{1, \ldots, 9\}, F k, \alpha(k)<T H \\
k 0 \quad \text { if } \quad \forall k F k, \alpha(k) \geq T H
\end{array}\right\}
$$

Normalizing the distances to the models enabled us to set a unique threshold $(\mathrm{TH}=10)$ for all the images independently of their size.

Brightness

Light conditions captured by a given picture are some of the most noticeable features involved in human aesthetic perception. Some information about the light condition is already explored by the previously described color analysis, however, analyzing the brightness provides an even more direct approach to evaluating the light conditions of a given image. There are several ways to measure the brightness of an image. For this study, we implemented analysis which target slightly different brightness contrasts.

$$
f_{26}=\frac{1}{M N} \sum_{m} \sum_{n} L(m, n)
$$

$$
f_{27}=\exp \left(\frac{255}{M N} \sum_{m} \sum_{n} \log \left(\epsilon^{+} \frac{L(m, n)}{255}\right)\right)
$$

422

where $L(m ; n)=\left(I_{r}(m ; n)+I_{g}(m ; n)+I_{b}(m ; n)\right) / 3$.

$f_{26}$ represents the arithmetic and $f_{27}$ the logarithmic average brightness; the latter takes the dynamic range of the brightness into account. Different images can therefore equal in one but differ in the other value. The contrast of brightness was assessed by defining $h_{l}$ as a histogram with 100 equally sized bins for brightness $L(m ; n)$, with $d$ as index for the bin with the maximum energy $h_{1}(d)=$ $\max \left(h_{1}\right)$. Two indices $a$ and $b$ were set as the interval $[a ; b]$ which contains $98 \%$ of the energy of $\mathrm{h}_{1}$. The histogram was then analyzed step by step towards both sides starting from the dth bin to identify $a$ and $b$. The first measure of the brightness contrast is then

$$
f_{28}=b-a+1
$$

431 For the second contrast quality feature a brightness histogram $h_{2}$ with 256 bins comprising the sum

of the gray-level histograms $h_{r}, h_{g}$ and $h_{b}$ generated from the red, green and blue channels:

$$
h_{2}(i)=h_{r}(i)+h_{g}(i)+h_{b}(i), \quad \forall i \in\{0, \ldots, 255\}
$$


434 The contrast quality $f_{29}$ is then the width of the smallest interval $\left[a_{2}, b_{2}\right]$ where $\sum_{i=a 2}^{b 2} h_{2}(i)>$ $4350.98^{\sum_{i=0}^{255}} h_{2}(i)$.

$$
f_{29}=b_{2}-a_{2}
$$

437 Edge features

438 Edge repartition was assessed by looking for the smallest bounding box which contains a chosen percentage of the energy of the edges, and compare its area to the area of the entire picture. Although Li and Chen (2009) and Ke et al. (2006) offer two different versions to target this feature, both use the absolute value of the output from a 3x3 Laplacian filter with $\alpha=0.2$. For color images the R, G and B channels are analyzed separately and the mean of the absolute values is used. At the boundaries the values outside the bounds of the matrix was considered equal to the nearest value in the matrix borders. According to Li and Chen (2009) the area of the smallest bounding box, containing $81 \%$ of the edge energy of their 'Laplacian image' ( $90 \%$ in each direction), was divided by the area of the entire image (figure S2 E - H).

$$
f_{30}=H_{90} W_{90} / H W
$$

$\mathrm{H}_{90}$ and $\mathrm{W}_{90}$ represent the height and width of the bounding box with $\mathrm{H}$ and $\mathrm{W}$ as the height and width of the image.

Ke et al. (2006) resized each Laplacian image initially to 100x100 and the image sum was normalized to 1 . Subsequently the area of the bounding box containing $96.04 \%$ of the edge energy (98\% in each direction) was established and the quality of the image was defined as $1-H_{98} W_{98}$, whereby $H_{98}$ and $W_{98}$ are the height and width of the bounding box.

$$
f_{31}=1-H_{98} W_{98} ; H_{98} \text { and } W_{98} \in[0,1]
$$

Resizing and normalizing the Laplacian images further allows for an easy comparison of different Laplacian images. Analog to Ke et al. (2006) who compared one group of professional quality photos and one group of photos of inferior quality, we can now consider two groups of images: one with pictures of pristine and one with pictures of degraded reefs. $M_{p}$ and $M_{s}$ represent the mean Laplacian image of the pictures in each of the respective groups. This allows a comparison of the Laplacian image $L$ with $M_{p}$ and $M_{s}$ using the $L 1$-distance.

$$
f_{32}=d_{s}-d_{p}, \quad \text { where }
$$




$$
d_{p}=\sum_{m, n}\left|L(m, n)-M_{p}(m, n)\right|
$$

464 The sum of edges $f_{33}$ was added as an additional feature not implemented by one of the above

465

466

467

468

469

470

471

472

473

474

475

476

477

478

479

480

481

482

483

484

485

486

487

488

489

490

491

mentioned studies. Sobel image $\mathrm{S}$ of a picture was defined as a binary image of identical size, with 1's assigned to edges present according to the Sobel method and 0's for no edges present. For a color image Sobel images $\mathrm{Sr}, \mathrm{Sg}$ and $\mathrm{Sb}$ were constructed for each of its red, green and blue channels and the sum of edges defined as

$$
f_{33}=\left(\left|S_{r}\right|_{L 1}+\left|S_{g}\right|_{L 1}+\left|S_{b}\right|_{L 1}\right) / 3
$$

\section{Texture analysis}

To analyze the texture of pictures more thoroughly we implemented features not yet discussed in Ke et al. (2006), Datta et al. (2006), or Li and Chen (2009). Therefore we considered $R_{H}$ to be a matrix of the same size as $I_{H}$, where each pixel $(m, n)$ contains the range value (maximum value - minimum value) of the 3-by-3 neighborhood surrounding the corresponding pixel in $I_{H} \cdot R_{S}$ and $R_{V}$ were computed in the same way for $I_{S}$ and $I_{V}$ and the range of texture was defined as

$$
f_{34}=\frac{1}{M N} \sum_{m} \sum_{n}\left(R_{H}(m, n)+R_{S}(m, n)+R_{V}(m, n)\right) / 3
$$

Additionally $D_{H}, D_{S}$, and $D_{V}$ were set as the respective matrix identical in size to $I_{H}$, $I_{S}$, and $I_{V}$, where each pixel $(m, n)$ contains the standard deviation value of the 3-by-3 neighborhood around the corresponding pixel in $I_{H}, I_{S}$, or $I_{V}$. The average standard deviation of texture was defined as:

$$
f_{35}=\frac{1}{M N} \sum_{m} \Sigma_{n}\left(D_{H}(m, n)+D_{S}(m, n)+D_{V}(m, n)\right) / 3
$$

The entropy of an image is a statistical measure of its randomness, and can also be used to characterize its texture. For a gray-level image, it is defined as $-\sum_{i=0}^{255} p(i) * \log _{2}(p(i))$ where $\mathrm{p}$ is a vector containing the 256 bin gray-level histogram of the image. Thus, we define features $f_{36}, f_{37}$ and $f_{38}$ as the entropy of $I_{r}, I_{g}$, and $I_{b}$ respectively.

$$
\begin{aligned}
& f_{36}=\operatorname{entropy}\left(I_{r}\right) \\
& f_{37}=\operatorname{entropy}\left(I_{g}\right) \\
& f_{38}=\operatorname{entropy}\left(I_{b}\right)
\end{aligned}
$$

\section{Wavelet based texture}

Texture feature analysis based on wavelets was conducted according to Datta et al. (2006). However concrete information on some of the implemented steps (e.g., norm or exact Daubechies wavelet used) was sometimes not available which may result in a slight deviation of the 
492 calculation. First a three level wavelet transformation on $I_{H}$ was performed using the Haar Wavelet 493 (see figure S2 I and J). A 2D wavelet transformation of an image yields 4 matrices: the 494 approximation coefficient matrix $C^{A}$ and the three details coefficient matrices $C^{H}, C^{V}$ and $C^{D}$. 495 Height and width of resulting matrices are $50 \%$ of the input image and $C^{H}$, $C^{V}$ and $C^{D}$ show 496 horizontal, vertical and diagonal details of the image. For a three-level wavelet transformation a 497 2D wavelet transformation is performed and repeated on the approximation coefficient matrix $C$ $498 \stackrel{A}{1}$ and repeated again on the new approximation coefficient matrix $C^{2}$, resulting in 3 sets of 499 coefficients matrices. The $i^{\text {th }}$-level detail coefficient matrices for the hue image $\mathrm{I}_{\mathrm{H}}$ were then 500 denoted as $C^{H}{ }^{i}, C^{i}$, and $C^{D} i(I \in\{1,2,3\})$. Features $f_{39}-f_{41}$ are then defined as follows:

$$
f_{38+i}=\frac{1}{S i} \sum_{m} \Sigma_{n} C_{i}^{H}(m, n)+C_{i}^{V}(m, n)+C_{i(m, n)), \quad i \in\{1,2,3\}}^{D}
$$

502 Where $\forall i \in\{1,2,3\}, S_{i}=\left|C^{i}\right|_{L 1}+\left|C^{V}\right|_{L 1}+\left|C^{i}\right|_{L 1}$. Features $f_{42}-f_{44}$ and $f_{45}-f_{47}$ are computed accordingly for $\mathrm{I}_{\mathrm{s}}$ and $\mathrm{I}_{\mathrm{v}}$. Features $f_{48}-f_{50}$ are defined as the sum of the three wavelet features for $H, S$, and $V$ respectively:

$$
f_{48}=\sum_{i=40}^{42} f_{i,} f_{49}=\sum_{i=43}^{45} f_{i,} f_{50}=\sum_{i=46}^{48} f_{i}
$$

Blur

Measurements of the image blur were done based on suggestions given by Li and Chen (2009) and Ke et al. (2006). Based on the information provided we were not able to implement the features successfully, thus the features presented here are a modified adaptation. For this purpose each picture was considered to be a blurred image $I_{\text {blurred }}$ as a result of the convolution of an hypothetical sharp version of the image $I_{\text {sharp }}$ and a Gausssian filter $G_{\sigma}: I_{\text {blurred }}=G_{\sigma} * I_{\text {sharp }}$. As the

512 Gaussian filter eliminates high frequencies only, the blur of a picture can be determined by quantifying the frequency of the image above a certain threshold $\theta$. A higher frequency indicates less blur. The threshold $\theta$ reduces the noise and provides a defined cutoff of the high frequencies.

515 To quantify blur in a given image, a 2D Fourrier Transform was performed resulting in Y. To avoid ambiguities the 2D Fourrier Transform is then normalized by $1 / \sqrt{M N}: Y=f f t 2\left(I_{\text {blurred }}\right)$ /

$517 \sqrt{M N}$. As we observed a phenomenon of spatial aliasing, only the frequencies $\left(m^{\prime}, n^{\prime}\right)$ where $0<$ $518 m^{\prime}<M / 2$ and $0<n^{\prime}<N / 2$ were used, resulting in

$$
f_{51}=\max \left(2 \frac{m^{\prime}-\left[\frac{M}{2}\right]}{M} ; 2 \frac{n^{\prime}-\left[\frac{N}{2}\right]}{N}\right)
$$


520 521

522

523

524

525

526

527

528

529

530

531

532

533

534

535

536

537

538

539

540

541

542

543

544

545

546

547

548

Where $\left|Y\left(m^{\prime}, n^{\prime}\right)\right|>\theta, 0<m^{\prime}<M / 2$, and $0<n^{\prime}<N / 2$. The threshold was set as $\theta=0.45$.

\section{Local features}

In addition to global features which provide information about the general aspect of a picture, local features consider fragments of the image. This approach focuses on objects captured in the photograph, while disregarding the overall composition, which is partly dependent on the camera operator. Objects corresponding to uniform regions can be detected with the segmentation process described in Datta et al. (2006). First the image is transformed in the LUV color space and the $\mathrm{K}$ means algorithm is used to create $\mathrm{K}$ color-based pixel cluster. Then a connected components analysis in an 8-connected neighborhood is performed to generating a list of all segments present. The 5 largest segments are denoted as $\mathrm{s}_{1}, \ldots \mathrm{s}_{5}$, in decreasing order. As most pictures contain many details resulting in noise, we applied a uniform blur with $\mathrm{m} \mathrm{x} \mathrm{m}$ ones matrix as kernel before the segmentation process.

\section{Rule of third}

A well-known paradigm in photography is that the main subject of attention in a picture should generally be in its central area. This rule is called the 'Rule of third' and the 'central area' can more precisely defined as the ninth of a photo divided by $1 / 3$ and $2 / 3$ of its height and width (see figure S2 A and B). Using HSV color space $f_{52}$ defines the average hue $\mathrm{H}$ for this region

$$
f_{52}=\frac{1}{\left(\left[\frac{2 M}{3}\right]-\left[\frac{M}{3}\right]+1\right)\left(\left[\frac{2 N}{3}\right]-\left[\frac{N}{3}\right]+1\right)} \sum_{m=\left[\frac{M}{3}\right]}^{\left.\sum^{2 M}\right]} \sum_{n=\left[\frac{N}{3}\right]}^{\left[\frac{N N}{3}\right]} I_{H}(m, n)
$$

$I_{S}$ and $I_{V}$ are computed accordingly with $f_{53}$ and $f_{54}$.

Focus region

Le and Chen (2009) offer a slightly different approach on the rule of thirds. The study suggests to use HSL color space and argue that focusing exclusively on the central ninth is too restrictive. From this approach, the focus region $F R$ was defined as the central ninth of the respective picture plus a defined percentage $\mu$ in its immediate surrounding (figure S2 A and B). For the here presented image analysis we set $\mu=0.1$.

$$
f_{55}=\frac{1}{\# \text { of }\{(m, n) \mid(m, n) \in F R\}} \sum_{(m, n) \in F R} I_{H_{-}}(m, n)
$$

$I_{S_{-}}$and $I_{L_{-}}$are computed accordingly with $f_{56}$ and $f_{57}$.

\section{Segmentation}



segments are denoted as $s_{1}, \ldots, s_{5}$. Our analysis focuses on the largest 3 or 5 segments only. Not only were the properties of each of these segments, but also the quantity of the connected segments in each picture recorded. This provides a proxy for the number of objects and the complexity of each recorded image.

$$
f_{58}=\# \text { of } L
$$

The number of segments $\mathrm{s}_{\mathrm{i}}$ in $L$ above a certain threshold $\left(f_{59}\right)$, and the size of the 5 largest segments $\mathrm{s}_{\mathrm{i}}\left(f_{60}-f_{64}\right)$ was defined as:

$$
\begin{aligned}
& f_{59}=\# \text { of }\left\{s_{i} \mid \# \text { of } s_{i}>M N / 100, i \in\{1, \ldots, 5\}\right\} \\
& f_{59+i}=\left(\# \text { of } s_{i}\right) / M N, \quad \forall \in\{1, \ldots, 5\}
\end{aligned}
$$

559 To gain information on the position of these 5 biggest segments, the image was divided in 9 equal parts identical to Rule of third feature analysis. Setting $\left(r_{i}, c_{i}\right) \in\{1,2,3\}^{2}$ as the indices of the row and column around the centroid of $\mathrm{s}_{\mathrm{i}}$, features $f_{65}$ through $f_{69}$ as were defined, starting on the top left of each image as

$$
f_{64+i}=10 * r+c, \forall \in\{1, \ldots, 5\}
$$

564

The average hue, saturation and value were then assessed for each of the objects. Features $f_{70}$ through $f_{74}$ were computed as the average hues of each of the segments $\mathrm{s}_{\mathrm{i}}$, in the HSV color space:

$$
f_{69+i}=\frac{1}{\# \text { of } s i} \sum_{(m, n) \in \text { si }} I_{H}(m, n), \quad \forall i \in\{1, \ldots, 5\}
$$

Features $f_{75}-f_{79}$ and $f_{80}-f_{84}$ are computed analog for $I_{S}$ and $I_{V}$ respectively. Features $f_{85}-f_{87}$ were further defined as the average brightness of the top 3 segments:

$$
f_{84+i}=\frac{1}{\# \text { of } s i} \sum_{(m, n) \in \text { si }} L(m, n), \quad \forall i \in\{1,2,3\}
$$

lightness $L(m, n)$ has already been defined under 'Brightness analysis'. This allows us to compare the colors of each of the segments and to evaluate their diversity by measuring the average color spread $f_{88}$ of their hues. As complementary colors are aesthetically more pleasing together $f_{89}$ was defined as the average complementary colors among the assessed segments.

$$
f_{88}=\sum_{i=1}^{5} \sum_{j=1}^{5}|h(i)-h(j)| \quad \text { and } \quad f_{89}=\sum_{i=1}^{5} \sum_{j=1}^{5}\|h(i)-h(j)\|_{a l}
$$

$$
\text { where } \forall_{i} \in 1, \ldots, 5, h(i)=f_{69+i} \text { is the average hue of } \mathrm{s}_{\mathrm{i}} \text {. }
$$


576 As round, regular and convex shapes are considered to be generally more beautiful, the presence 577 of such shapes in a picture should increase its aesthetic value. Here we only assessed the shapes 578 of the 3 largest segments in each image. The coordinates of the centers of mass (first-order 579 moment), the variance (second-order centered moment) and skewness (third-order centered 580 moment) was calculated for each of these segments was calculated by defining for all $i \in\{1,2,3\}$

$$
\begin{aligned}
& f_{89+i}=\overline{x_{i}}=\frac{1}{\# \text { of } s i} \sum_{(m, n) \in \text { si } x(m, n)} \\
& f_{92+i}=\overline{y_{i}}=\frac{1}{\# \text { of } s i} \sum_{(m, n) \in \text { si } y(m, n)}
\end{aligned}
$$

.

84

\section{where $\forall(m, n),(x(m, n), y(m, n))$ are the normalized coordinates of pixel $(m, n)$.}

Horizontal and vertical coordinates were normalized by height and width of the image to account for different image ratios. To quantify convex shapes in an image $f_{102}$ was defined as the percentage of image area covered by convex shapes. To reduce noise only $\mathrm{R}$ segments $\mathrm{p}_{1}, \ldots, \mathrm{p}_{\mathrm{R}}$ containing more than $M N / 200$ pixels were incorporated in this feature. The convex hull $g_{k}$ was then computed for each $p_{k}$. A perfectly convex shape $p_{k} \cap g_{k}=p_{k}$ and $\frac{\operatorname{area}(p k)}{\operatorname{area}(g k)}=1$ would be too restrictive for our purposes of analyzing natural objects, so $p_{k}$ was considered convex if $\frac{\operatorname{area}(p k)}{\operatorname{area}(g k)}>\delta$.

$$
f_{102}=\frac{1}{M N} \sum_{k=1 I}^{R}\left(\frac{\operatorname{area}(p k)}{\operatorname{area}(g k)}>\delta\right) *\left|\operatorname{area}\left(p_{k}\right)\right|
$$

where $I(\bullet)$ is the indicator function and $\delta=0.8$.

The last features using segmentation measure different types of contrast between the 5 largest segments. Features $f_{103}-f_{106}$ address the hue contrast, the saturation contrast, the brightness contrast, and the blur contrast. First the average hue, saturation, brightness, and the blur for each $\mathrm{S}_{\mathrm{i}}$ was calculated

$$
\begin{aligned}
& h(i)=\frac{1}{\# \text { of } s i} \sum_{(m, n) \in \text { si } I_{H}(m, n),} \quad \forall i \in\{1, \ldots, 5\} \\
& s(i)=\frac{1}{\# \text { of } s i} \sum_{(m, n) \in \text { si } I_{S}(m, n),} \quad \forall i \in\{1, \ldots, 5\}
\end{aligned}
$$$$
l(i)=\frac{1}{\# \text { of } s i} \sum_{(m, n) \in \text { si }} L(m, n), \quad \forall i \in\{1, \ldots, 5\}
$$

To calculate the blur of the segment $s_{i}, I_{s i}$ was computed so that 


$$
I_{S i}(m, n)=\left\{\begin{array}{cc}
(\operatorname{Ir}(m, n)+\operatorname{Ir}(m, n)+\operatorname{Ir}(m, n)) / 3 \text { if }(m, n) \in \text { si } \\
0 \quad \text { otherwise }
\end{array}\right.
$$

603 604

605

606

607

608

609

610

611

612

613

614

615

M1, ..., M16, numbered in row-major order. Applying the notations of the 'Wavelet based texture', $\stackrel{H}{C^{3}}, C^{3}$, and $C^{3}$ denote the third level detail coefficient matrices generated by performing a

and $b(i)$ defined as blur measure of $I_{s i}$ for all $i \in\{1, \ldots, 5\}$, analog to the previously described 'Blur measure'

$$
b(i)=\max \left(2 \frac{m^{\prime}-\left[\frac{M}{2}\right]}{M} ; 2 \frac{n^{\prime}-\left[\frac{N}{2}\right]}{N}\right)
$$

where $\left|Y_{i}\left(m^{\prime}, n^{\prime}\right)\right|>\theta, 0<m^{\prime}<M / 2$ and $0<n^{\prime}<N / 2$, with $Y_{i}=f f t 2\left(I_{s i}\right) / \sqrt{M N}$ and $\theta=0.45$. Features $\mathrm{f}_{103}-\mathrm{f}_{106}$ were then defined as

$$
\begin{aligned}
& f_{103}=i, j \in\{1, \ldots, 5\}\left(|| h(i)-h(j) \|_{a l}\right) \\
& \max _{104}=i, j \in\{1, \ldots, 5\}(|s(i)-s(j)|) \\
& \max _{105}=i, j \in\{1, \ldots, 5\}(|l(i)-l(j)|) \\
& \max _{106}=i, j \in\{1, \ldots, 5\}(|b(i)-b(j)|)
\end{aligned}
$$

Low depth of field indicators

Finally, according to the method described by Datta et al. (2006) to detect low depth of field (DOF) and macro images, we divided the images into 16 rectangular blocks of identical size three-level Haar wavelet transform on the hue channel of the image. The low DOF for the hue is then computed as

$$
f_{107}=\frac{\sum_{(m, n) \in M 6 M 7 M 10 M 11}\left(C_{3}^{H}(m, n)+C_{3}^{V}(m, n)+C_{3}^{D}(m, n)\right)}{\sum_{i=1}^{16} \sum_{(m, n) \in M i}\left(C_{3}^{H}(m, n)+C_{3}^{V}(m, n)+C_{3}^{D}(m, n)\right)}
$$

and $f_{108}$ and $f_{109}$ are calculated similarly for saturation and value.

\section{Machine learning}

To reduce the noise and decrease the error, we analyzed multiple methods of determining feature importance. An unsupervised random forest approach was used to identify the most important features (figure S1). For every tree in the construction of a random forest, an out-of-bag sample was sent down the tree for calculation and the number of correct predictions was recorded. The variable importance was then generated by comparing the number of correct predictions from 
628 the out-of-bag sample to a randomly permuted variant. For each feature, the resulting importance 629 is:

630

\section{5}

$$
\frac{1}{n_{\text {trees }}} \sum_{\text {all trees }}\left(R_{O O B}-R_{\text {perm }}\right)
$$

A second method was to identify redundant columns before the training. Using a covariance matrix of the 109 features, relationships between columns were analyzed and columns with a correlation greater than 0.90 were clustered into groups. Within every group, features were either directly or mutually related. In order to not compromise the comprehensive approach of the coral reef aesthetic feature analysis the most important features from each group remained in the analysis while highly correlated, less important features within a group were removed. We built neural networks based on these two methods and discerned when removing redundant features we obtained lower mean square errors. Thus, we utilized a total of 97 features when building our ensemble of neural networks.

To fuse the predictive power of the 109 aesthetic features, a Levenberg-Marquardt algorithm was used simultaneously on every sample of the training set to minimize the mean squared error of the estimated output score and the NCEAS value. Typical mean squared error rates were in the $90 \mathrm{~s}$. We then decided on a threshold of 60 for the mean squared error and searched the weight space of the neural network to find 10 sets of weights with a mean squared error of less than 60 on the validation set. The predicted NCEAS scores of these 10 networks were then averaged for the ensemble prediction, which is our aesthetic value.

After running test data through the ensemble of neural networks, we further analyze the accuracy of our system by simultaneously testing multiple pictures at a time. To see how much more reliably we could deduce the NCEAS score using N pictures from the same site, we averaged the outputs from our ensemble of neural networks for all twenty choose $\mathrm{N}(\mathrm{N}=1,2,3,4,5)$ combinations available from the test batch. Combinations of multiple pictures increased the accuracy of the root mean square error of 6.57 for $\mathrm{N}=1$ to 5.35 for $\mathrm{N}=2,4.88$ for $\mathrm{N}=3$, and 4.46 for both $\mathrm{N}=4$ and $\mathrm{N}=5$.

\section{Acknowledgements}


657 We thank the biosphere foundation for providing the pictures of Carysfort reef.

658

659

660

661

662

663

664

665

666

667

668

669

670

671

672

673

674

675

676

677

678

679

680

681

682

683

684

685

686

687

688

689

690

691

\section{References}

Adams EQ. 1943. Chromatic Valence as a Correlate of Munsell Chroma. Proceedings of the Twenty-Eighth Annual Meeting of the Optical Society of America, Pittsburg, PA 33(12):683.

Adorno TW. 1997. Aesthetic theory. Bloomsbury Publishing

Bakhtin M. 1941. Rabelais and His World. Trans. Hélène Iswolsky. Bloomington: Indiana University Press, 1993

Baumgarten AG, Baumgarten N. 1735. Meditationes Philosophicae De Nonnvllis Ad Poema Pertinentibvs: Qvas Amplissimi Philosophorvm Ordinis Consensv Ad D. Septembris MDCCXXXV. Grvnertus.

Bellwood DR, Hughes TP, Folke C, Nystrom M. 2004. Confronting the coral reef crisis. Nature 429: 827-833.

Beza BB. 2010. The aesthetic value of a mountain landscape: A study of the Mt. Everest Trek. Landscape and Urban Planning 97:306 - 317.

Birkhoff GD. 1933. Aesthetic measure. Harvard University Press, Cambridge

Carr A. 2002. Grass roots and green tape. Principles and practices of environmental stewardship. Federation Press, Sydney

Casalegno S, Inger R, DeSilvey C, Gaston KJ. 2013. Spatial Covariance between Aesthetic Value \& Other Ecosystem Services. PLoS One 8(6), e68437.

Cesar H, Burke L, Pet-Soede L. 2003. The economics of worldwide coral reef degradation. Cesar Environmental Economics Consulting, Beatherlands.

Chatterjee A. 2014. Neuroaesthetics - Researchers unravel the biology of beauty and art. The Scientist

Cope ED. 1890. Review of: Poulton, E.B. 1890. Poulton on the Colors of Animals. The colors of animals, their meaning and use, especially considered in the case of insects. American Naturalist 24:927-932.

Costerton JW, Stewart PS, Greenberg EP. 1999. Bacterial biofilms: a common cause of persistent infections. Science 284:1318-1322. 
692 Curtis VA. 2007. Dirt, disgust and disease: a natural history of hygiene. Journal of Epidemiology and Community

693

694

695

696

697

698

699

700

701

702

703

704

705

706

707

708

709

710

711

712

713

714

715

716

717

718

719

720

721

722

723

724

725

726

727 Health 61:660-664.

Datta R, Joshi D, Li J, Wang JZ. 2006. Studying aesthetics in photographic images using a computational approach. In Computer Vision-ECCV 2006 (pp. 288-301). Springer Berlin Heidelberg.

Dinsdale EA, Fenton DM. 2006. Assessing coral reef condition: Eliciting community meanings. Society \& Natural Resources 19:239-258.

Dinsdale EA, Pantos O, Smriga S, Edwards R, Angly F, Wegley L, Hatay M, Hall D, Brown E, Haynes M, Krause L, Sala E, Sandin SA, Thurber RV, Willis BL, Azam F, Knowlton N, Rohwer F. 2008. Microbial ecology of four coral atolls in the northern Line Islands. PLoS One 3:1584.

Dinsdale EA. 2009. Linking ecological and perceptual assessments for environmental management: A coral reef case study. Ecology and Society 14:1-17.

Dutton D. 2006. A naturalist definition of art. The Journal of Aesthetics and Art Criticism 64:367-377.

Fenton DM, Syme GJ. 1989. Perception and evaluation of the coastal zone: Implications for coastal zone planning. Coastal Management 17:295-308.

Fenton DM, Young M, Johnson VY. 1998. Re-presenting the Great Barrier Reef to tourists: Implications for tourist experience and evaluation of coral reef environments. Leisure Sciences 20:177-192.

Foerschner A. 2011. Paul McCarthy und die Entertainment-Metropole Los Angeles: Aspekte zur Produktion und Rezeption eines multimedialen Kunstkonzepts. Ludwig-Maximilians-Universität, Munich.

Foerschner A. 2013. The fairest in the land: the deconstruction of beauty in Paul McCarthy's WS, Afterimage - The Journal for Media Arts and Cultural Criticism 41:4-18.

Haas AF, Knowles B, Lim YW, Somera TM, Kelly LW, Hatay M, Rohwer F. 2014. Unraveling the unseen players in the ocean-a field guide to water chemistry and marine microbiology. Journal of Visualized Experiments 93e52131-e52131.

Halpern BS, Shaun Walbridge S, Selkoe KA, Kappel CV, Micheli F, D'Agrosa C, Bruno JF, Casey KS, Ebert C, Fox HE, Fujita R, Heinemann D, Lenihan HS, Madin EMP, Perry MT, Selig ER, Spalding M, Steneck R, Watson R. 2008. A global map of human impact on marine ecosystems. Science 319:948-952.

Hawkins DE, Lamoureux K. 2001. Global growth and magnitude of ecotourism. The encyclopedia of ecotourism 6372

Hertz R. 2012. That's disgusting; Unraveling the mysteries of repulsion, New York/London: W. W. Norton \& Company. 2012, pp.44-76.

Hoegh-Guldberg O, Mumby PJ, Hooten AJ, Steneck RS, Greenfield P, Gomez E, Harvell CD, Sale PF, Edwards AJ, Caldeira K, Knowlton N, Eakin CM, Iglesias-Prieto R, Muthiga N, Bradbury RH, Dubi A, Hatziolos ME. 2007 Coral reefs under rapid climate change and ocean acidification. Science 318:1737-1742.

Hoffman RE, Palmer JF. 1996. Silviculture and forest aesthetics within stands. The New York Center for Forestry Research and Development, Pub. \#2, State University of New York, College of Environmental Sciences and Forestry, Syracuse, NY 
728

729

730

731

732

733

734

735

736

737

738

739

740

741

742

743

744

745

746

747

748

749

750

751

752

753

754

755

756

757

758

759

760

761

762

763

Hurlbert AC, Ling YL. 2007. Biological components of sex differences in color preference. Current Biology 17:623625.

Jackson JBC, Kirby MX, Berger WH, Bjorndal KA, Botsford LW, Bourque BJ, Bradbury RH, Cooke R, Erlandson J, Estes JA, Hughes TP, Kidwell S, Lange CB, Lenihan HS, Pandolfi JM, Peterson CH, Steneck RS, Tegner MJ, Warner RR. 2001. Historical overfishing and the recent collapse of coastal ecosystems. Science 293:629638.

Jacobsen T, Höfel L. 2002. Aesthetic judgments of novel graphic patterns: analyses of individual judgments. Perceptual and Motor Skills 95:755-766.

Joblove GH, Greenberg D. 1978. Color spaces for computer graphics. Computers \& Graphics 12:20-25.

Jokiel PL, Brown EK, Friedlander A, Rodgers SKU, Smith WR. 2004. Hawai'i coral reef assessment and monitoring program: Spatial patterns and temporal dynamics in reef coral communities. Pacific Scienc 58:159-174.

Kant I. 1790. Kritik der Urteilskraft, Frankfurt aM: Suhrkamp Verlag (1974): 237-41.

Kaufman L. 2005. One Fish Two Fish Red Fish Blue Fish: Why Are Coral Reefs so Colorful? National Geographic 86-109.

Kaufman L, Sandin S, Sala E, Obura D, Rohwer F, Tschirky T. 2011. Coral Health Index (CHI): measuring coral community health. Science and Knowledge Division, Conservation International, Arlington, VA, USA.

Ke Y, Tang X, Jing F. 2006. The design of high-level features for photo quality assessment. Proceedings Computer Vision and Pattern Recognition IEEE 1:419-426.

Knowlton N. 2001. The future of coral reefs. Proceedings of the National Academy of Science USA 98:5419-5425.

Knowlton N, Jackson JB. 2008. Shifting baselines, local impacts, and global change on coral reefs. PLoS biology, 6:e54.

Kolnai A. 2004. On disgust. Open Court Publishing, Peru Illinois

Li C, Chen T. 2009. Aesthetic visual quality assessment of paintings. IEEE Journal of Selected Topics in Signal Processing 3:236-252.

Marshall NJ. 2000. Communication and camouflage with the same 'bright' colours in reef fishes. Philosophical Transactions of the Royal Society B 355:1243-1248.

Martin-Lopez B, Iniesta-Arandia I, Garcia-Llorente M, Palomo I, Casado-Arzuaga I, García Del Amo D, GómezBaggethun E, Oteros-Rozas E, Palacios-Agundez I, Willaarts B, González JA, Santos-Martín F, Onaindia M, Cesar López-Santiago C, Montes C. 2012 Uncovering ecosystem service bundles through social preferences. PLoS One 7(6): e38970. doi:10.1371/journal.pone.0038970.

McDole T, Nulton J, Barott KL, Felts B, Hand C, Hatay M, Lee H, Nadon MO, Nosrat B, Salamon P, Bailey B, Sandin SA, Vargas-Angel B, Youle M, Zgliczynski BJ, Brainard RE, Rohwer F. 2012. Assessing coral reefs on a Pacific-wide scale using the microbialization score. PLoS One 7:e43233.

Menninghaus W. 2012. Disgust: Theory and history of a strong sensation. SUNY Press

Miller ML, Auyong J. 1991. Coastal zone tourism: A potent force affecting environment and society. Marine Policy 15:75-99. 
764

765

766

767

768

769

770

771

772

773

774

775

776

777

778

779

780

781

782

783

784

785

786

787

788

789

790

791

792

793

794

795

796

797

798

799

Neto F. 2003. A new approach to sustainable tourism development: Moving beyond environmental protection. Natural Resources Forum 27:212-222.

Onians J. 2007. Neuroarthistory: From Aristotle and Pliny to Baxandall and Zeki. New Haven, CT: Yale University Press

Oppenheimer DM, Frank MC. 2008. A rose in any other font would not smell as sweet: Effects of perceptual fluency on categorization. Cognition 106:1178-1194.

Palmer SE, Schloss KB. 2010. An ecological valence theory of human color preference. Proceedings of the National Academy of Science USA 107:8877-8882.

Palmer SE, Griscom WS. 2013. Accounting for taste: Individual differences in preference for harmony. Psychonomic Bulletin \& Review 20:453-461.

Pandolfi JM, Bradbury RH, Sala E, Hughes TP, Bjorndal KA, Cooke RG, McArdle D, McClenachan L, Newman MJH, Paredes G, Warner RR, Jackson JB. 2003. Global trajectories of the long-term decline of coral reef ecosystems. Science 301:955-958.

Pandolfi JM, Jackson JBC, Baron N, Bradbury RH, Guzman HM, Hughes TP, Kappel CV, Micheli F, Ogden JC, Possingham HP, Sala E. 2005. Are US coral reefs on the slippery slope to slime? Science 307:1725-1726.

Peterson CH, Lubchenco J. 1997. Marine ecosystem services. Nature's Services: Societal Dependence on Natural Ecosystems. Edited by GC Daily. Island Press, Washington, DC 177-194

de Pinho JR, Grilo C, Boone RB, Galvin KA, Snodgrass JG. 2014. Influence of aesthetic appreciation of wildlife species on attitudes towards their conservation in Kenyan agropastoralist communities. PLoS One 9:e88842. doi:10.1371/journal.pone.0088842.

Preskitt LB, Vroom PS, Smith CM. 2004. A rapid ecological assessment (REA) quantitative survey method for benthic algae using photo quadrats with SCUBA. Pacific Science 58:201-209.

Reber R, Winkielman P, Schwarz N. 1998. Effects of perceptual fluency on affective judgments. Psychological Science 9:45-48.

Reber R, Schwarz N, Winkielman P. 2004. Processing fluency and aesthetic pleasure: Is beauty in the perceiver's processing experience? Personality and Social Psychology Reviews 8:364-82.

Reber R. 2012. Processing fluency, aesthetic pleasure, and culturally shared taste. Aesthetic science: Connecting minds, brains, and experience 223-249

Richet C. 1984. Les causes du dégoût. In: Richet C (Ed) L'homme et l'intelligence. Fragments de physiologie et de psychologie (pp. 41-84) Paris, Alcan

Rozin P, Fallon AE. 1987. A perspective on disgust. Psychological Review 94:23-41.

Rozin P, Schull J. 1988. The adaptive-evolutionary point of view in experimental psychology. In: Atkinson RC, Herrnstein RJ, Lindzey G, Luce RD (Eds) Handbook of Experimental Psychology (pp. 503-546). New York: Wiley-Interscience.

Rubner Y, Tomasi C, Guibas LJ. 2000. The Earth Mover's Distance as a metric for image retrieval. International Journal of Computer Vision 40:99-121. 
800

801

802

803

804

805

806

807

808

809

810

811

812

813

814

815

816

817

818

819

820

821

822

823

824

825

826

827

828

829

830

831

832

833

Sandin SA, Smith JE, DeMartini EE, Dinsdale EA, Donner SD, Friedlander AM, Konotchick T, Malay M, Maragos JE, Obura D, Pantos O, Gustav Paulay G, Richie M, Rohwer F, Schroeder RE, Walsh S, Jackson JBC, Knowlton N, Sala E. 2008. Baselines and degradation of coral reefs in the northern Line Islands. PLoS One 3:e1548.

Seppelt R, Dormann CF, Eppink FV, Lautenbach S, Schmidt S. 2011. A quantitative review of ecosystem service studies, approaches, shortcomings and the road ahead. Journal of Applied Ecology 48:630-636.

Sheppard SRJ. 2004. Visual analysis of forest landscapes. Planning 44:177-198.

Silvera DH, Josephs RA, Giesler RB. 2002. Bigger is better: The influence of physical size on aesthetic preference judgments. Journal of Behavioral Decision Making 15:189-202.

Van den Berg AE, Vlek CA, Coeterier JF. 1998. Group differences in the aesthetic evaluation of nature development plans: a multilevel approach. Journal of Environmental Psychology 18(2):141-157.

Wilkinson C. 2004. Status of coral reefs of the world: 2004. Townsville (Queensland, Australia): Australian Institute of Marine Science

(1)

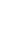

\section{Figure legends}

Figure 1) Map of sampling sites with representative images and NCEAS scores. The upper 4 images show images of the benthic community in the respective Caribbean sites, the lower images represent the sampling sites throughout the tropical Pacific.

Figure 2) Boxplots of coral reef aesthetic values at each site and regression of coral reef aesthetic values vs. NCEAS scores across all assessed reef sites. Panel A (Test) shows coral reef aesthetic values calculated for 200 images on which the previously trained machine learning algorithm was tested. Panel B (Training) shows the generated coral reef aesthetic values from 1970 images used to improve the feed forward neural networks that optimized the importance of features or feature groups in generating a single coral reef aesthetic value.

Figure 3) The top panel (A) shows microbial cell abundance at 7 reef sites. Panel B shows the distribution of pictures with respective aesthetic values at each of those sites. Blue bars show the amount of pictures with the respective aesthetic value used in the training set $(n=1897)$, red bars show the amount of pictures from the test set $(n=220)$. The insert $C$ shows the regression between 
834 mean microbial cell abundance and mean aesthetic value (training + test) across all 7 sampling 835 sites.

836

837 Figure 4) Examples of pictures with their respective generated aesthetic values from two 838 contrasting sampling sites, Kingman and Kiritimati. Aesthetic values for pictures A and B, which 839 resemble representative images of the specific locations, were close matches to the NCEAS score 840 at the respective site. Pictures $\mathrm{C}$ and $\mathrm{D}$ give examples of pictures which resulted in mismatches to 841 the respective NCEAS score.

842

843 Figure 5) Images A - E are taken at the identical location on Carysfort reef, U.S. Caribbean, over 844 a time span of 40 years (photos taken by P Dustan). The aesthetic value calculated for each picture 845 shows a significant degradation of aesthetic appearance during this period. The historic images 846 from 1975 indicate that the aesthetic appearance of this Caribbean reef was comparable to present 847 day pristine reefscapes as for example on Palmyra atoll in the Central Pacific (F, photo taken by $\mathrm{J}$ 848 Smith).

849

Figure S1) Relative importance of all 109 features derived from a random forest approach. Features are grouped into three general feature groups, texture of the entire image (texture), color and brightness of the entire image (color), and size, color and brightness, and distribution of objects within the image (objects).

Figure S2) Example pictures of a healthy (left) and a degraded reef (right). The applied measurements for brightness contrast across the whole image $f 28$ shows 97 for A and 47 for B. The green lines depict the central focus region which outlines the segment of interest used for 'Rule of Third' features. The orange line marks the Focus region used for features $f_{55}$ through $f_{56}$, where an additional margin $(\mu=0.1)$ has been included. C and D show pictures after segmentation by $\mathrm{K}$ means, using $\mathrm{K}=2$ and $\mathrm{m}=1$. From these images the number of connected components can

861 be calculated by implementing feature $f_{58}(\mathrm{C}=1470, \mathrm{D}=2369)$. Panel $\mathrm{E}$ and $\mathrm{G}$ show the Laplacian image produced for feature $f_{30}, \mathrm{~F}$ and $\mathrm{H}$ show the resized and normalized Laplacian image which serves as basis for the calculation of $f_{31}$. The blue bounding boxes contain $81 \%(\mathrm{E}=0.623, \mathrm{G}=$ $0.611)$ and $96.04 \%(F=0.089, \mathrm{H}=0.079)$ of the edge energy respectively. Panel I and $\mathrm{J}$ show the 
866 overview of color models used to compare the analyzed images, or objects within images against. 867 The bar chart shows the average NCEAS score where pictures matching to the respective color 868 model were taken. The red boxes indicate the model that fits best to image A and B respectively. 
1

Map of sampling sites

Map of sampling sites with representative images and NCEAS scores. The upper 4 images show images of the benthic community in the respective Caribbean sites, the lower images represent the sampling sites throughout the tropical Pacific.

Klein Curacao: 13.07 CuracaoSeaqu: 31.95 Curacaobuoy2: 49.19 Barbuda: 49.39

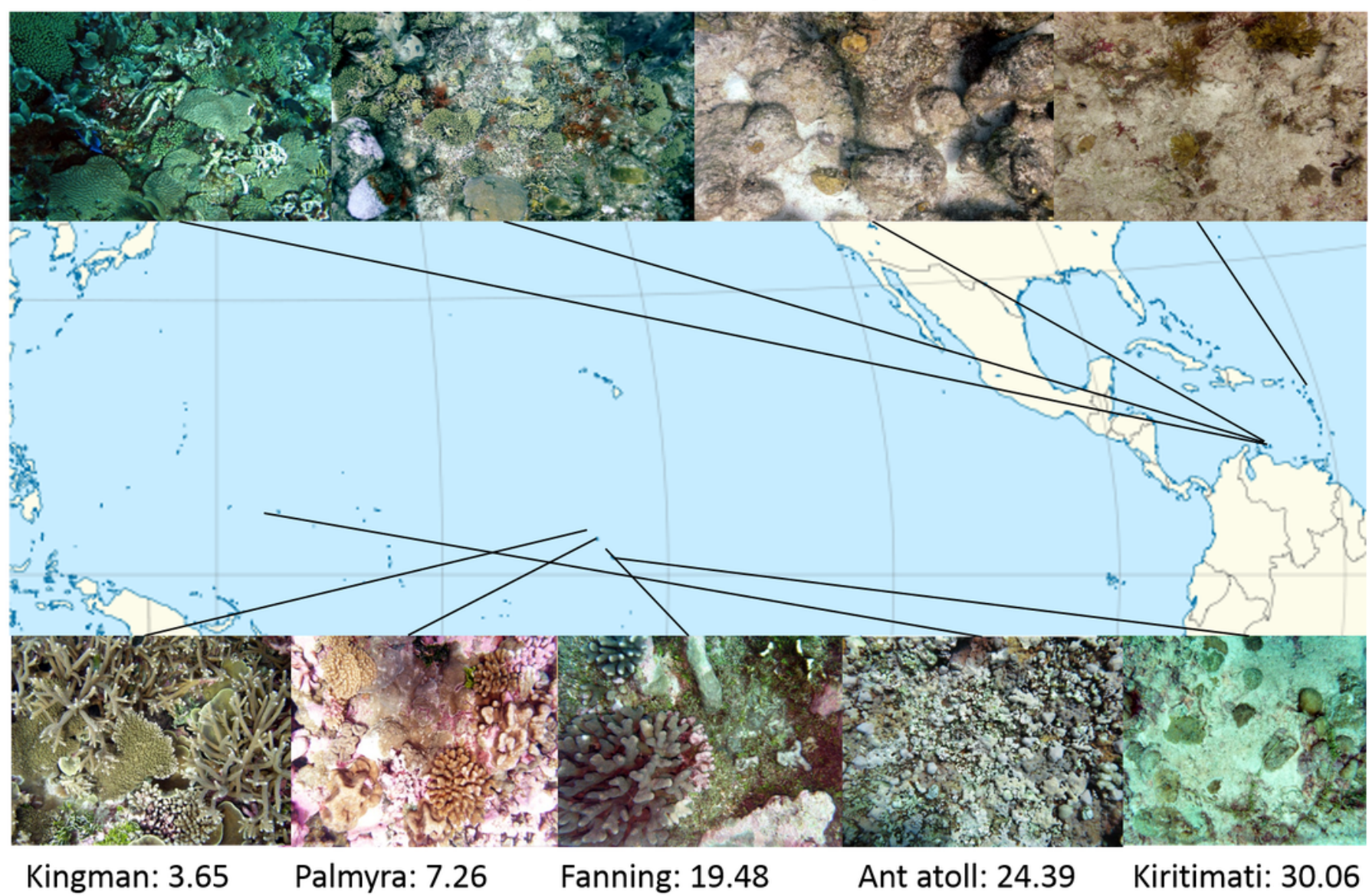


2

Coral reef aesthetic values

Boxplots of coral reef aesthetic values at each site and regression of coral reef aesthetic values vs. NCEAS scores across all assessed reef sites. Panel A (Test) shows coral reef aesthetic values calculated for 200 images on which the previously trained machine learning algorithm was tested. Panel B (Training) shows the generated coral reef aesthetic values from 1970 images used to improve the feed forward neural networks that optimized the importance of features or feature groups in generating a single coral reef aesthetic value.

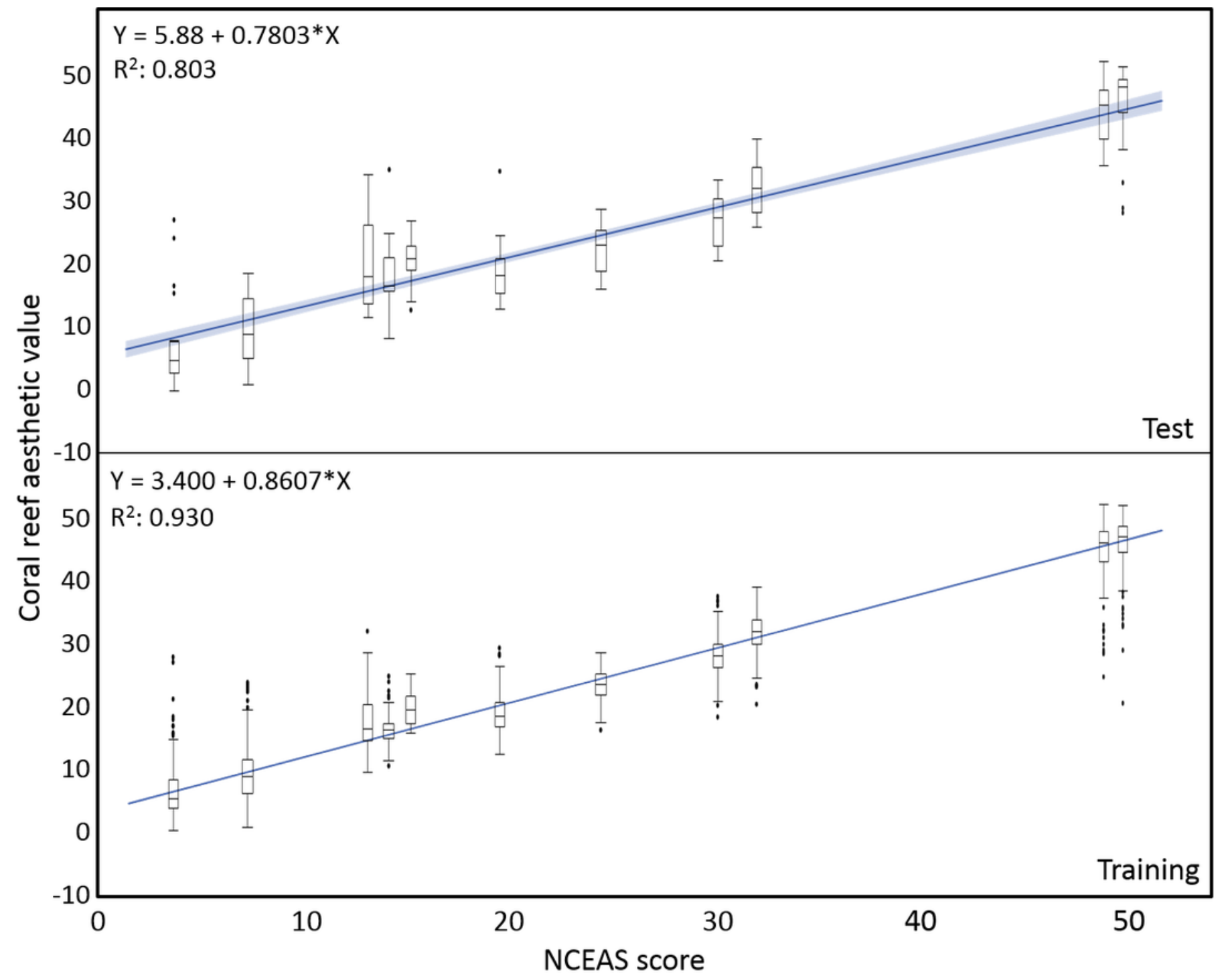


3

Distribution of aesthetic values

The top panel (A) shows microbial cell abundance at 7 reef sites. Panel B shows the distribution of pictures with respective aesthetic values at each of those sites. The insert $C$ shows the regression between mean microbial cell abundance and mean aesthetic value (training + test) across all 7 sampling sites.

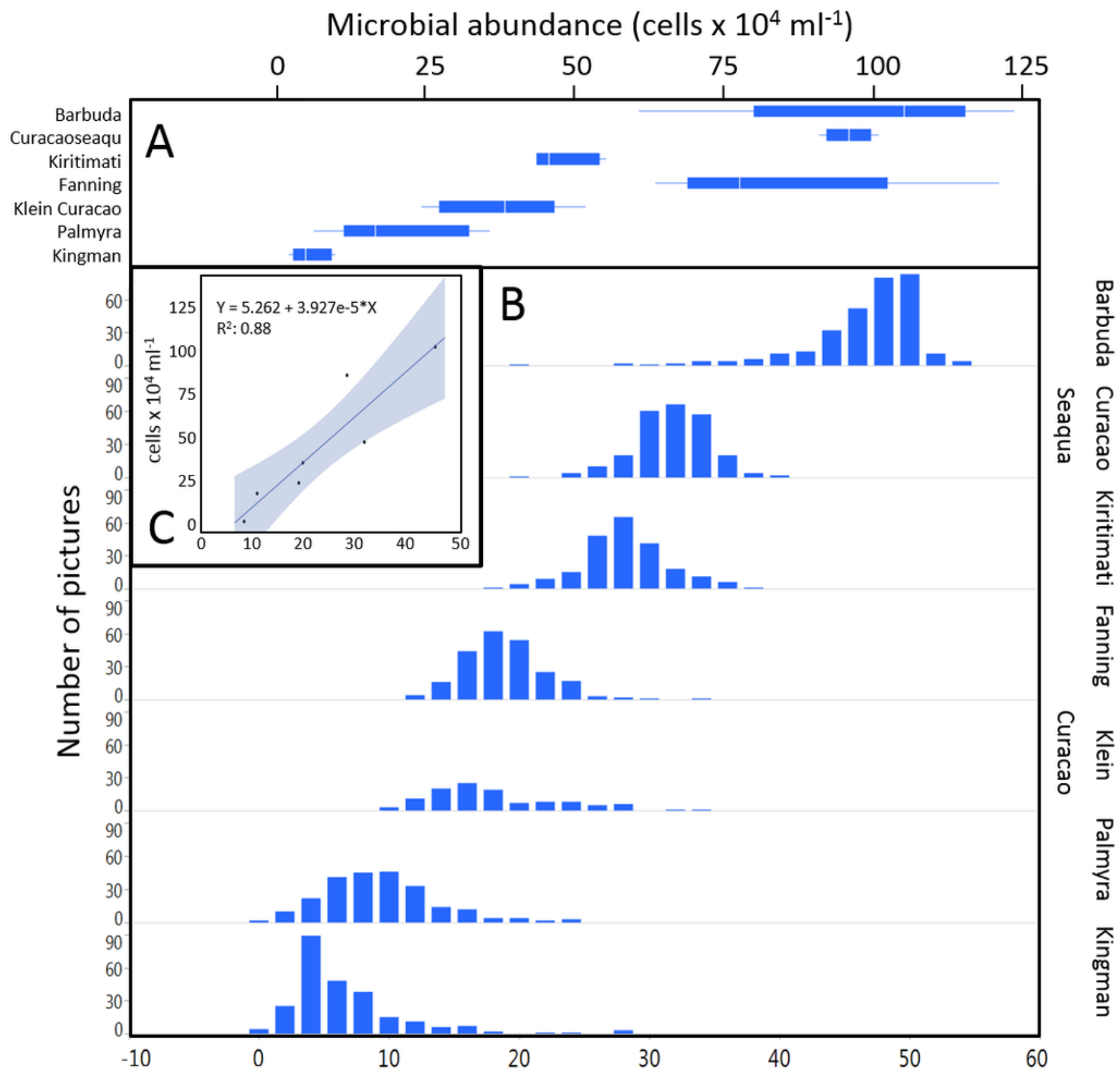




\section{4}

Image examples

Examples of pictures with their respective generated aesthetic values from two contrasting sampling sites, Kingman and Kiritimati. Aesthetic values for pictures $A$ and $B$, which resemble representative images of the specific locations, were close matches to the NCEAS score at the respective site. Pictures $C$ and $D$ give examples of pictures which resulted in mismatches to the respective NCEAS score. 
Kingman

\section{NCEAS: 3.65}

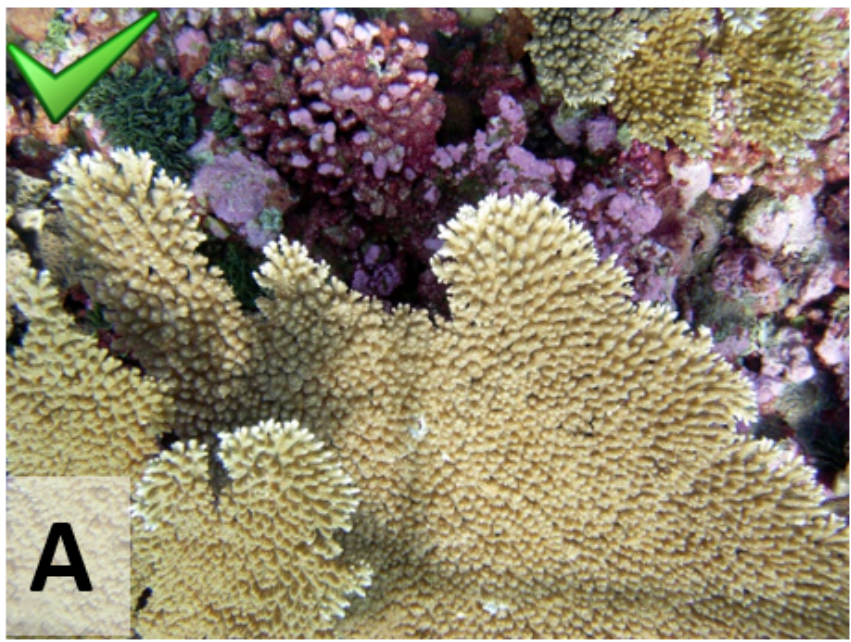

Aesthetic value: 3.51

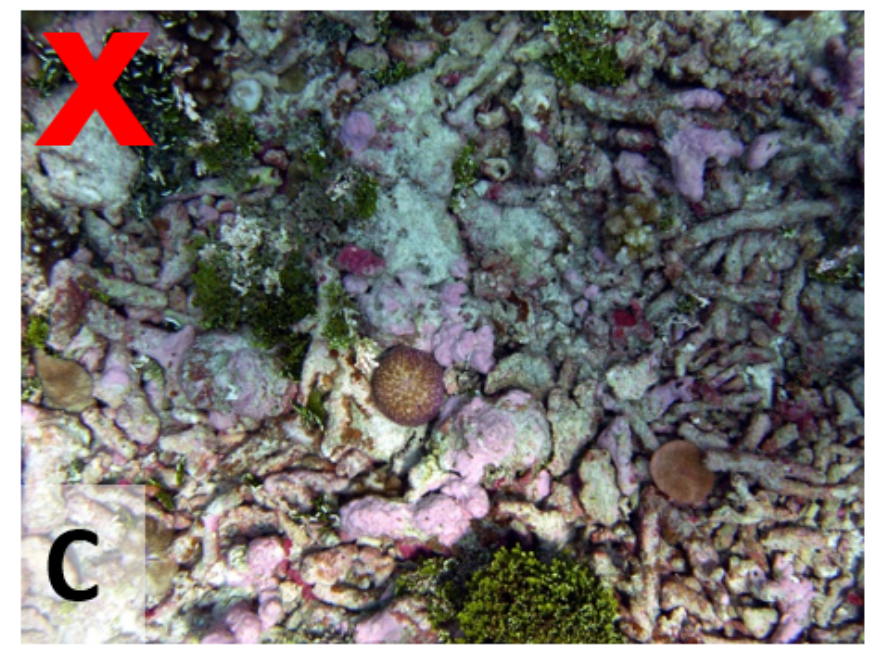

Aesthetic value: 19.72
Kiritimati

NCEAS:30.06

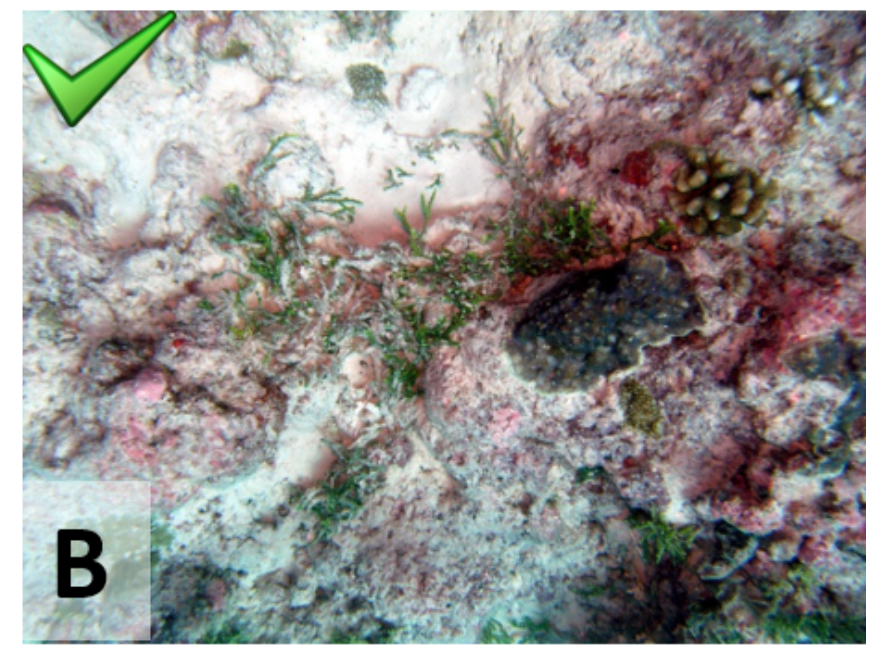

Aesthetic value: 30.05

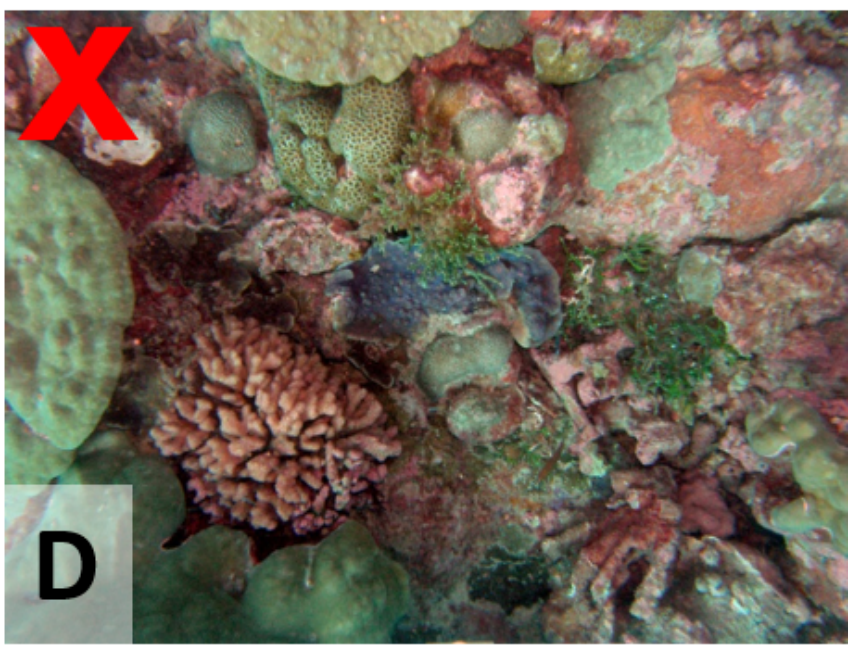

Aesthetic value: 13.83 
Figure 5 (on next page)

Aesthetic values of Carysfort reef

Images A - E are taken at the identical location on Carysfort reef, U.S. Caribbean, over a time span of 40 years (photos taken by P Dustan). The aesthetic value calculated for each picture shows a significant degradation of aesthetic appearance during this period. The historic images from 1975 indicate that the aesthetic appearance of this Caribbean reef was comparable to present day pristine reefscapes as for example on Palmyra atoll in the Central Pacific (F, photo taken by J Smith). 
A) Carysfort reef 1975: 11.44
D) Carysfort reef 2004:

35.50

둔.

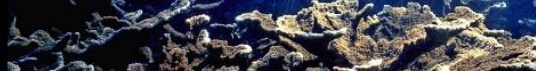

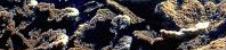

s.

3

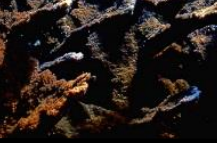

B) Carysfort reef 1985 :

12.42

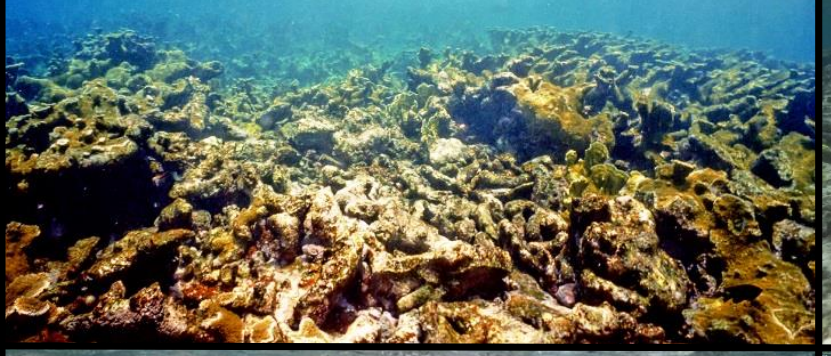

C) Carysfort reef 1995:

21.25

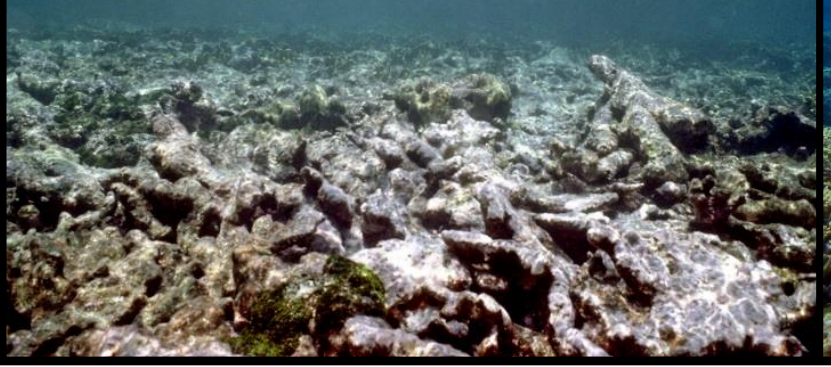

E) Carysfort reef 2014:

32.49
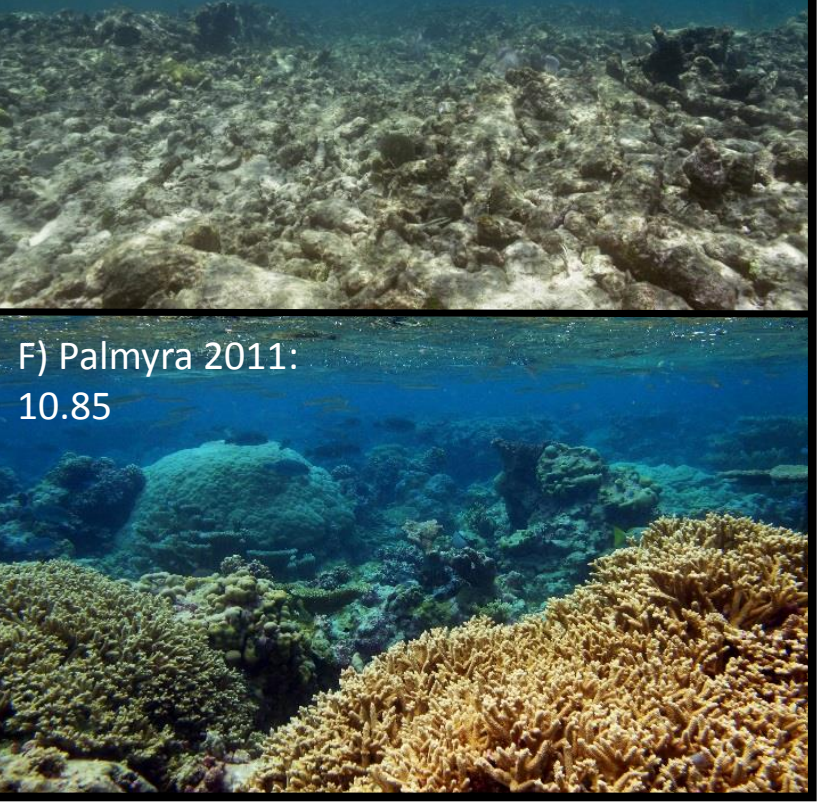